\title{
Evaluation of median urinary iodine concentration cut-off for defining iodine deficiency in pregnant women after a long term USI in China
}

Huidi Zhang ${ }^{1+}$, Meng $\mathrm{Wu}^{2+}$, Lichen Yang ${ }^{1 *}$ D, Jinghuan $\mathrm{Wu}^{1}$, Yichun $\mathrm{Hu}^{1}$, Jianhua Han ${ }^{3}$, Yunyou Gu${ }^{4}$, Xiuwei $\mathrm{Li}^{4}$, Haiyan Wang ${ }^{4}$, Liangkun $\mathrm{Ma}^{5^{*}}$ and Xiaoguang Yang ${ }^{1 *}$

\begin{abstract}
Background: The WHO/UNICEF/ICCIDD define iodine deficiency during pregnancy as median urinary iodine concentration $(\mathrm{MUIC}) \leq 150 \mu \mathrm{g} / \mathrm{L}$. China implemented universal salt iodization (USI) in 1995, and recent surveillance showed nationwide elimination of iodine deficiency disorders (IDD). Data from 2014 showed that the MUIC in 19, 500 pregnant women was $154.6 \mu \mathrm{g} / \mathrm{L}$ and $145 \mu \mathrm{g} / \mathrm{L}$ in 9000 pregnant women in 2015. However, symptoms of iodine deficiency were absent. Our study sought to evaluate whether MUIC below $150 \mu \mathrm{g} / \mathrm{L}$ affects thyroid function of Chinese pregnant women and their newborns in Chinese context.

Methods: We screened 103 women with normal thyroid function and MUIC lower than $150 \mu \mathrm{g} / \mathrm{L}$ during week 6 of pregnancy at Peking Union Medical College Hospital. Patient demographics and dietary salt intake were recorded. Subjects were followed at 12, 24, and 32 gestational weeks. At each visit, a 3-day dietary record, drinking water samples, and edible salt samples were collected and analyzed for total dietary iodine intake. Additionally, 24-h urine iodine and creatinine were measured. Blood tests assessed thyroid function in both mothers and newborns.

Results: Of 103 pregnant women enrolled, 79 completed all follow-up visits. Most subjects maintained normal thyroid function throughout pregnancy. However, 19 had thyroid dysfunction based on thyroid stimulating hormone and free thyroxine levels. The median serum iodine was $71 \mu \mathrm{g} / \mathrm{L}(95 \% \mathrm{Cl}: 44,109)$. The median thyroglobulin was $<13 \mu \mathrm{g} / \mathrm{L}$. values above this level indicate iodine deficiency in pregnant women. The median dietary iodine intake during pregnancy, derived from the 3-day record and measures of water and salt, was $231.17 \mu \mathrm{g} / \mathrm{d}$. Assuming $90 \%$ urinary iodine excretion (UIE), $200.11 \mu \mathrm{g} / \mathrm{d}$ UIE means the $222.34 \mu \mathrm{g}$ iodine loss per day, suggesting that subjects had a positive iodine balance throughout pregnancy. All neonatal blood samples showed TSH levels lower than $10 \mathrm{mIU} / \mathrm{L}$, indicating normal thyroid function. No significant difference was found among gestational weeks for urinary iodine, and the MUIC in subjects who completed 3 follow-up visits was $107.41 \mu \mathrm{g} / \mathrm{L}$.
\end{abstract}

Conclusion: Twenty years after implementing USI, expectant Chinese mothers with MUIC of $107.4 \mu \mathrm{g} / \mathrm{L}$, less than the WHO's $150 \mu \mathrm{g} / \mathrm{L}$ benchmark, maintained thyroid function in both themselves and their newborn babies.

Keywords: Urinary iodine, Chinese pregnant woman, Thyroid function

\footnotetext{
* Correspondence: yanglc@ninh.chinacdc.cn; Maliangkun@pumch.cn; xgyang@vip.sina.com

${ }^{+}$Huidi Zhang and Meng Wu contributed equally to this work.

${ }^{1}$ The Key Laboratory of Trace Element Nutrition, National Institute for

Nutrition and Health, Chinese Center for Disease Control and Prevention, 29

Nan Wei RoadXicheng District, Beijing, China

${ }^{5}$ Department of Obstetrics-gynecology, Peking Union Medical College

Hospital, No.1 Shuaifuyuan WangfujingDongcheng District, Beijing, China

Full list of author information is available at the end of the article
}

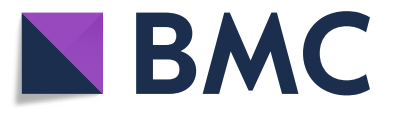

(c) The Author(s). 2019 Open Access This article is distributed under the terms of the Creative Commons Attribution 4.0 International License (http://creativecommons.org/licenses/by/4.0/), which permits unrestricted use, distribution, and reproduction in any medium, provided you give appropriate credit to the original author(s) and the source, provide a link to the Creative Commons license, and indicate if changes were made. The Creative Commons Public Domain Dedication waiver (http://creativecommons.org/publicdomain/zero/1.0/) applies to the data made available in this article, unless otherwise stated. 


\section{Background}

Iodine, one of the essential trace elements in the body, is required for the production of thyroid hormones, which are necessary for fetal cognitive development. Severe iodine deficiency during pregnancy can cause irreversible damage to the nervous system and intelligence of the fetus [1]. Iodine status in pregnancy is a focus of several current studies. The median urinary iodine concentration (MUIC) is a commonly used indicator to assess iodine status because the majority of iodine is excreted in urine [2, 3]. A joint task force of the World Health Organization (WHO), the United Nations Children's Fund (UNICEF), and the International Council for the Control of Iodine Deficiency Disorders (ICCIDD) [4] recommends that the MUIC of pregnant women be between 150 and $249 \mu \mathrm{g} / \mathrm{L}$. MUIC less than $150 \mu \mathrm{g} / \mathrm{L}$ has been defined as iodine deficiency.

China once had one of the world's greatest rates of iodine deficiency diseases (IDD). In 1995, a program of universal salt iodization (USI) was introduced to eradicate the deficiency [5]. Since then, the iodine nutrition level of Chinese residents has improved. IDD reached the level of sustained elimination in 2000 [6] and was eliminated on the national level as of the 2014 surveillance. The latest Chinese monitoring data showed that the iodine nutritional status of the general population, especially in children ages 8-10 years old, has already reached the appropriate level [7]. But according to the 2015 Chinese Adult Chronic Disease and Nutritional Surveillance (CACDNS), the MUIC of pregnant women in more than $50 \%$ of the provinces was less than $150 \mu \mathrm{g}$ / L (unpublished). This study involved 9000 pregnant women with a MUIC of $145 \mu \mathrm{g} / \mathrm{L}$, yet mothers in this study did not exhibit symptoms of iodine deficiency or thyroid dysfunction. Therefore, determining whether MUIC $<150 \mu \mathrm{g} / \mathrm{L}$ affects thyroid function in pregnant women and their newborns is of interest.

The aim of this study was to evaluate the thyroid function of Chinese pregnant women with MUIC below $150 \mu \mathrm{g} / \mathrm{L}$ throughout gestation. Additionally, our results may potentially provide data to support the salt iodization policy in China.

\section{Hypothesis}

In this study, we postulated two things: 1) if thyroid function during each trimester of pregnancy is normal, the total iodine intake is positively balanced compared with the excretion of urine iodine, and 2) if the thyroid stimulating hormone (TSH) of the newborn is normal, the mothers' iodine nutritional status during pregnancy is at a satisfactory level. MUIC of less than $150 \mu \mathrm{g} / \mathrm{L}$ in pregnant women may not cause compromised thyroid function in either women or newborns in this China population.

\section{Methods}

\section{Procedures}

To verify our hypothesis, we carried out a study in Beijing Peking Union Medical College Hospital. Subjects were enrolled at the first antenatal visit at the 6th week of pregnancy. To verify the current threshold of $150 \mu \mathrm{g} /$ L MUIC recommended by WHO/UNICEF/ICCIDD [4] and to test our hypothesis, volunteers were enrolled if they had normal thyroid function. This included negative thyroglobulin antibody (TgAb) and thyroid peroxidase antibody (TPOAb) but apparent iodine deficiency, based on morning spot urine iodine concentration lower than $150 \mu \mathrm{g} / \mathrm{L}$. During routine examinations in the 12th, 24th, and 32nd gestational weeks, thyroid function (including free triiodothyronine (FT3), free thyroxine (FT4), TSH, thyroid globulin (Tg) and serum iodine (SI)), dietary iodine intake, and 24-h urinary iodine and creatinine excretion were assessed. Following the birth of the child, neonatal heel blood was also tested for TSH to evaluate the thyroid function of the newborn. The schedule of visits is detailed in Fig. 1.

Because of large physiological fluctuations in thyroid biomarkers and lack of clear definition of "normal" thyroid function during pregnancy, we consulted an endocrinologist for subjects having a one-time abnormal thyroid function test. If the doctor determined that medical intervention for thyroid dysfunction was not indicated and thyroid testing after the next visit was normal, the subject could still be included in our analysis.

\section{Participants}

Subjects were recruited from the Obstetric Clinic of Peking Union Medical College Hospital between June 2016 and May 2017. Basic demographic information such as name, age, ID number, and contact method, was collected. Inclusion criteria included a spot urinary iodine concentration less than $150 \mu \mathrm{g} / \mathrm{L}$, TSH lower than $2.5 \mathrm{mIU} / \mathrm{L}$, and negative TPOAb and TgAb. Additionally, the women had to be pregnant with a single fetus in good physical condition. These women were enrolled following the informed consent and ethical review. The exclusion criteria were as follows: (1) subjects who had personal history and family history of thyroid disease; (2) subjects with a visible or palpable goiter; (3) subjects who took thyroid-related medicine; and (4) pregnant women who had some other gynecologic condition, such as uterine fibroids. In order to improve the compliance of our subjects, we set up free lectures to explain the related health care knowledge of pregnancy while also emphasizing the importance of dietary records and drinking water/edible salt sample collection in each trimester. 


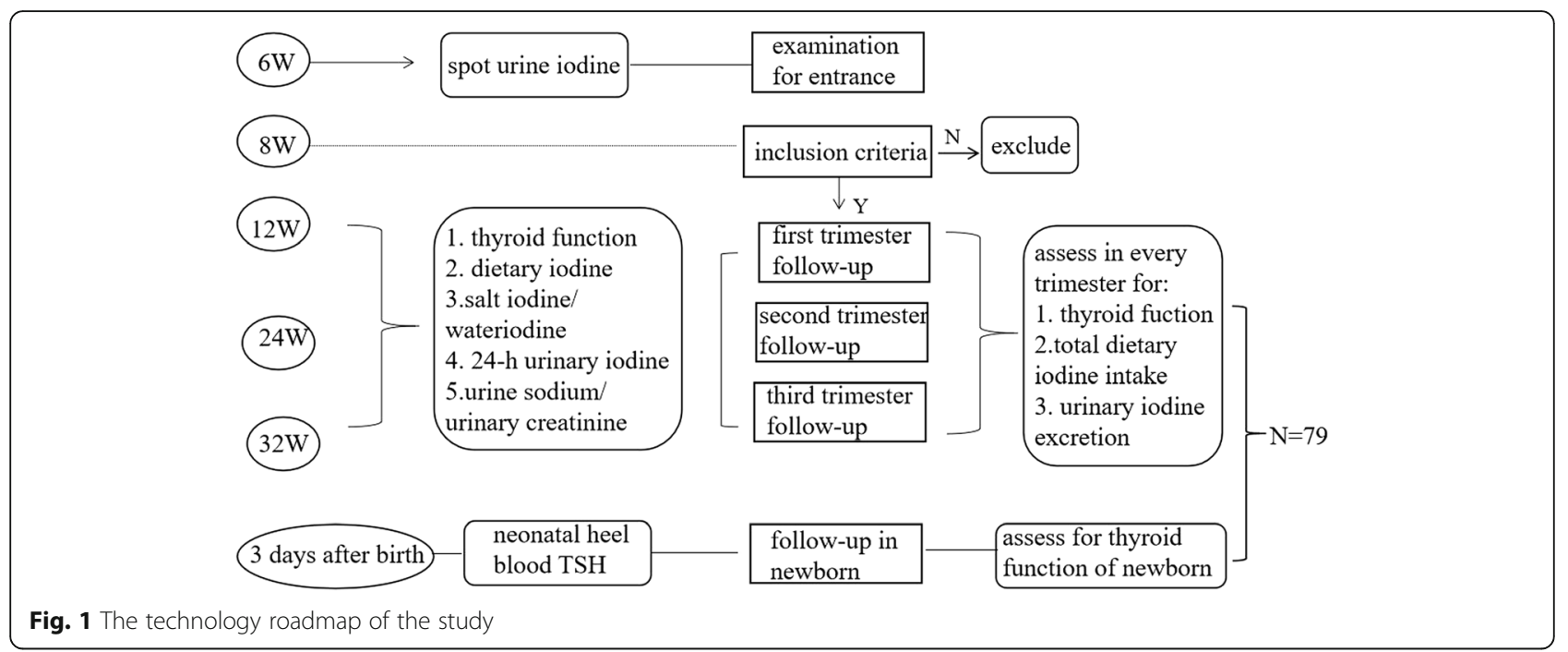

\section{Blood sample collection and analysis}

Venous blood samples to assess thyroid function and iodine status were collected during routine antenatal care and included FT3, FT4, TSH, Tg, SI, TgAb, and TPOAb. Serum FT3, FT4, and TSH were measured by an automatic chemiluminescence immunoanalyzer (Centaur XP, Siemens, Germany). Tg, TgAb, and TPOAb were tested using an automatic immune analyzer (Cobas, Roche Diagnostics, Tokyo, Japan), and SI was detected by inductively coupled plasma mass spectrometry (ICPMS; Thermo Fisher Scientific, Waltham, MA). These analyses were performed at the laboratory department of Beijing Peking Union Medical College Hospital. Diagnostic criteria for abnormal thyroid function are shown in Table 1.

Newborn TSH, obtained from heel blood samples collected 3 to 4 days after birth, is also a sensitive indicator of iodine deficiency in pregnancy $[9,10]$. This work is part of the Beijing Neonatal Disease Screening Center.

Table 1 Thyroid function in relation to plasma levels of TSH and FT4

\begin{tabular}{lll}
\hline Thyroid function & TSH $(\mathrm{mlU} / \mathrm{L})^{\mathrm{a}}$ & $\mathrm{FT} 4(\mathrm{pmol} / \mathrm{L})^{\mathrm{b}}$ \\
\hline Normal thyroid function & $0.1-3$ & $10.42-24.32$ \\
Isolated hypothyroxinemia & $0.1-3$ & $<10.42$ \\
Subclinical hypothyroidism & $>3$ & $10.42-24.32$ \\
Clinical hypothyroidism & $>3$ & $<10.42$ \\
Subclinical hyperthyroidism & $<0.1$ & $10.42-24.32$ \\
Clinical hyperthyroidism & $<0.1$ & $>24.32$
\end{tabular}

${ }^{a}$ Normal range for TSH (mlU/L) [8]: 0.13-3.93 (T1), 0.26-3.50 (T2), and $0.42-3.85$ (T3)

${ }^{\mathrm{b}}$ Normal range for FT4 (pmol/L) 10.42-24.32 pmol/L referred the value of clinical practice in Peking Union Medical College Hospital

\section{4-h urine collection and analysis}

Following enrollment, all participants received detailed instruction for the 24-h urine collection. From the 12th gestational week, they were asked to collect the 24-h urine the day before their routine prenatal examination. After complete remixing in the urine bag, participants accurately measured and recorded the total volume of urine collected using the measuring cups provided. Subjects then aliquoted the remixed urine into two $50 \mathrm{~mL}$ tubes which were kept and sent to the hospital for further assessment. If the urine samples could not be sent for analysis in a timely manner, they were stored at $4{ }^{\circ} \mathrm{C}$. One tube was tested by the Laboratory of Beijing Peking Union Medical College Hospital for the detection of sodium content and creatinine (AU7200, Beckman Coulter, Brea, CA). The other tube of urine was transported to the National Iodine Deficiency Disease Reference Laboratory for measurement of urinary iodine concentration by As-Ce catalysis spectrophotometry, the gold standard method for estimating iodine content in salt [11]. Urinary iodine level was tested as described, and the 24-h urinary iodine excretion was calculated by urinary iodine concentration $\times$ urinary volume.

\section{Dietary total iodine analysis and sample collection}

Total dietary iodine was measured from food, iodized salt, and water. Three days before each routine examination, participants were asked to record all foods, soups, and drinking water in a 3-day dietary record. An electronic dietary scale was provided to each subject to weigh all foods and water. Trained health workers answered any questions and checked the dietary records on the day of clinical follow-up. The iodine content in food was calculated using reference values from the 
China Food Composition database (2009) and our laboratory database. In addition, participants collected 20 $\mathrm{g}$ of edible salt and $50 \mathrm{~mL}$ of drinking water for analysis of salt and water iodine content. This testing was carried out by the National IDD Reference Laboratory.

The calculation for edible salt iodine intake was salt intake $\times$ salt iodine content $\times(1-$ the loss rate of cooking). We adopted a cooking loss rate of $20 \%$, which is recommended by the WHO/UNICEF/ICCIDD [4]. The salt intake was calculated by the standard method of 24$\mathrm{h}$ urine sodium content $(\mathrm{mmol}) \times$ molar mass of sodium chloride $(\mathrm{g} / \mathrm{mol}) / 1000$. Twenty-four-hour urine sodium excretion has become the preferred method of obtaining data on salt intake in population surveys [11].

The actual amount of drinking water was recorded, and the amount of soup was calculated from the 3-day dietary record. Water iodine intake of each pregnant woman was calculated via this formula: the sum of drinking water and soups $(\mathrm{mL}) \times$ the iodine content of water / $\mathrm{mL}$.

\section{Statistical analysis}

General statistical analysis was performed using SAS 9.4 (SAS Institute, Cary, NC). A $P$-value less than 0.05 was considered statistically significant. The normality distribution tests were performed on all the data. If the indices were not normally distributed, they were presented as a median (P2.5, P97.5). The others, which did follow normal distributions, were expressed as mean \pm standard deviations $(\bar{X} \pm \mathrm{SD})$. This study adopted the normal percentile method to formulate the reference range for some indices, and it could be represented by P2.5-P97.5. Because urinary iodine concentration (UIC) and thyroid function may be affected by some factors more than others, we conducted a one-way analysis of variance (ANOVA) to analyze the influence of other factors. The comparison of constituent ratio and rate was carried out using Chi-squared test. In order to explore changes in thyroid function at several gestations, the indices were analyzed by variance analysis of repeated measurement starting from 6 weeks' gestation. Pearson's ProductMoment Coefficient was employed to examine the correlation of indices that followed a normal distribution. Spearman's rank correlation coefficient was used to analyze the association between other indicators which did not obey a normal distribution.

\section{Results}

\section{Baseline characteristics of subjects}

A total of 103 pregnant women were enrolled in this study, and 79 finished all 3 follow-up visits. Twenty-four participants were lost to follow-up for a variety of reasons, such as inconvenience of the 24-h urine collection and 3-day dietary record or after refusing the blood draw for thyroid function monitoring. There was no significant difference between those who completed all visits and those lost to follow-up, as analyzed through baseline characteristics. Having subjects lost to follow-up did not impact the analysis in this study.

After screening for inclusion criteria, we obtained the urinary iodine distribution of the satisfactory samples. No significant difference was found between UIC and thyroid function according to different demographic factors, including age, nationality, education, occupation, and income. The UIC at 6 weeks' gestation had a normal distribution with a mean of $85 \mu \mathrm{g} / \mathrm{L}$. The TSH and FT4 were in the normal range with the average level of these two indices being $1.45 \mathrm{mIU} / \mathrm{L}$ and $15.76 \mathrm{pmol} / \mathrm{L}$, respectively.

\section{Distribution and assessment of thyroid function in different trimesters}

Our cohort of 79 pregnant women each underwent thyroid function tests 4 times during the study. There were significant differences among serum FT3, FT4, TSH, SI, and $\mathrm{Tg}$ across trimesters (Table 2). The FT3 and FT4 of pregnant women at 3 follow-up visits were significantly different compared with the values from the 6th gestational week $(P<0.05)$. Starting from 6 weeks' gestation, the level of FT3 and FT4 decreased gradually, and turned to be smooth at 24th weeks. The levels of TSH first decreased and then rose to a " $U$ " shape. Comparison of TSH in any trimester with the former period, found that it was significantly different. SI also decreased with time; when compared with the first trimester, the 24th and 32nd weeks were significantly different. With respect to FT3 and FT4, although there was a significant difference between 12th and the 24th and 32nd weeks, there was no significant difference between the 24th and 32nd weeks. Similar to TSH, Tg also had a U-shaped curve. The value of $\mathrm{Tg}$ in the 12th, 24th, 32nd gestational weeks was $8.91 \mu \mathrm{g} / \mathrm{L}, 7.74 \mu \mathrm{g} / \mathrm{L}$, and $9.92 \mu \mathrm{g} / \mathrm{L}$, respectively.

At 6 weeks' gestation, all 79 pregnant women had normal thyroid function (Table 3). During pregnancy, 19 subjects experienced thyroid dysfunction once, and 1 subject had it twice. The rate of thyroid dysfunction in 12th, 24th, and 32nd gestational weeks was 8.9, 6.4, and $11.5 \%$, respectively. There was no significant difference in thyroid function by trimester $(P>0.05)$.

Total dietary iodine intake during the entire pregnancy A total of 237 samples of drinking water and edible salt were collected during the 3 follow-up visits (Table 4). The median (inter-quartile range (IQR) water iodine content was $2.0 \mu \mathrm{g} / \mathrm{L}(0.4-2.9 \mu \mathrm{g} / \mathrm{L})$. There was no difference in water iodine content from different sources such as tap water, bottled water, or filtered water. The amount of 
Table 2 Comparison of Thyroid function parameters in different gestation

\begin{tabular}{lllllll}
\hline Gestation & $\mathrm{N}$ & $\begin{array}{l}\mathrm{FT3} \\
(\mathrm{pmol} / \mathrm{L})\end{array}$ & $\begin{array}{l}\text { FT4 } \\
(\mathrm{pmol} / \mathrm{L})\end{array}$ & $\begin{array}{l}\text { TSH } \\
(\mathrm{m} / \mathrm{U} / \mathrm{L})\end{array}$ & $\begin{array}{l}\mathrm{Sl} \\
(\mu \mathrm{g} / \mathrm{L})\end{array}$ & $\begin{array}{l}\text { TG } \\
(\mu \mathrm{g} / \mathrm{L})\end{array}$ \\
\hline 6th & 79 & $4.74 \pm 0.52$ & $16.01 \pm 2.00$ & $1.48 \pm 0.65$ & - & - \\
12 th & 79 & $4.44 \pm 0.56^{\mathrm{a}}$ & $15.38 \pm 1.97^{\mathrm{a}}$ & $1.08 \pm 0.70^{\mathrm{a}}$ & $80.11 \pm 15.72$ & $8.91(6.83 \sim 15.22)$ \\
24th & 78 & $3.90 \pm 0.36^{\mathrm{ab}}$ & $12.59 \pm 1.51^{\mathrm{ab}}$ & $1.58 \pm 0.63^{\mathrm{b}}$ & $68.99 \pm 13.39^{\mathrm{b}}$ & $7.74(5.03 \sim 12.98)^{\mathrm{b}}$ \\
32th & 78 & $3.94 \pm 0.78^{\mathrm{ab}}$ & $12.62 \pm 1.84^{\mathrm{ab}}$ & $1.74 \pm 0.73^{\mathrm{abc}}$ & $69.14 \pm 15.75^{\mathrm{b}}$ & $9.92(6.19 \sim 16.33)^{\mathrm{c}}$ \\
F & & 50.36 & 132.61 & 32.61 & 38.39 & 14.24 \\
$P$ value & & $<0.0001$ & $<0.0001$ & $<0.0001$ & $<0.0001$ & $<0.0001$ \\
\hline
\end{tabular}

FT3 Free Triiodothyronine, FT4 Free Thyroxine, TSH Thyroid Stimulating Hormone, SI serum iodine, TG thyroid globulin. ${ }^{a} p<0.05$ between each trimesters with the 6th weeks; ${ }^{\mathrm{b}} p<0.05$ between each trimesters with the 12 th weeks; ${ }^{c} p<0.05$ between each trimesters with the 24 th weeks

water intake included drinking water and soup. There was no significant difference in water iodine intake throughout the pregnancy: $3.12 \mu \mathrm{g} / \mathrm{d}, 3.58 \mu \mathrm{g} / \mathrm{d}$ and $3.23 \mu \mathrm{g} / \mathrm{d}$, in the 1st, 2nd, and 3rd trimesters, respectively.

The median (IQR) iodine content of edible salt was measured as $22.84 \mathrm{mg} / \mathrm{kg}(21.15-25.49 \mathrm{mg} / \mathrm{kg})$. According to the results, the coverage rate of iodized salt was $100 \%$ and edible rate of adequately iodized salt was $94 \%$ (In this study, $25 \mathrm{mg} / \mathrm{kg}$ iodine in edible salt in Beijing was adopted as the standard from China's standard [GB 26878-2011], the allowance range was $18-33 \mathrm{mg} / \mathrm{kg}$ ). The mean value of 24 -h urine sodium content was $144.96 \mathrm{mmol}$, and the salt intake in this study was calculated as $8.48 \mathrm{~g} / \mathrm{d}$. Therefore, the average total salt iodine intake during the 3 trimesters was as follows: $140.04 \mu \mathrm{g} /$ d, $153.25 \mu \mathrm{g} / \mathrm{d}$, and $163.09 \mu \mathrm{g} / \mathrm{d}$.

The food iodine intake in each trimester was $59.62 \mu \mathrm{g} /$ $\mathrm{d}, 63.22 \mu \mathrm{g} / \mathrm{d}$, and $62.51 \mu \mathrm{g} / \mathrm{d}$, respectively. The total dietary iodine intake was $218.14 \mu \mathrm{g} / \mathrm{d}$ in the 1 st trimester, $233.51 \mu \mathrm{g} / \mathrm{d}$ in the 2nd, and $243.66 \mu \mathrm{g} / \mathrm{d}$ in the $3 \mathrm{rd}$. There was no significant difference in the intake of food iodine, edible salt iodine, and total dietary iodine at different stages of pregnancy.

\section{Distribution and comparison of urine indices}

The median volume of 24-h urine was $1863 \mathrm{~mL}$ (Table 5). The MUIC and urinary iodine excretion (UIE) of all participants were $107.41 \mu \mathrm{g} / \mathrm{L}$ (IQR 83.84$150.13 \mu \mathrm{g} / \mathrm{L}$ ) and $200.11 \mu \mathrm{g} / \mathrm{d}$ (IQR $152.75-265.50 \mu \mathrm{g} / \mathrm{d}$ ), respectively. There were no significant differences in these three indicators between the trimesters.
Because 24-h urine is not easy to collect, we usually measure the content of creatinine to correct for its influence on the UIE. The median urine creatinine excretion (UCE) was nearly $1 \mathrm{~g} / \mathrm{d}$, and the amount of UCE increased throughout gestation $(P<0.01)$, which was consistent with other reports [11]. Creatinine was used as a correction factor to minimize the variation in urine volume for its relatively constant excretion rate [12]. These data also demonstrated the good quantity of the 24-h urine collection in our study. On the other hand, the correlation coefficient of MUIC and UIE was lower than that of creatinine-adjusted urine iodine (UICr) and UIE (0.575 vs 0.733$)$, suggesting that after correcting for creatinine, UICr can reflect the iodine status better than MUIC. There was also significant difference among the median urine creatinine (MUC) in the trimesters.

\section{Serum concentration of thyroid function indices in different UIC groups}

Table 6 depicts serum concentrations of FT3, FT4, TSH, $\mathrm{SI}$, and $\mathrm{Tg}$ in different UIC groups. Compared with the 150-249 $\mu \mathrm{g} / \mathrm{L}$ UIC group, Tg was significantly lower in the $250-499 \mu \mathrm{g} / \mathrm{L}$ UIC group. In contrast, serum SI was significantly higher in the $250-499 \mu \mathrm{g} / \mathrm{L}$ UIC group compared with the 150-249 $\mu \mathrm{g} / \mathrm{L}$ UIC group. FT3, FT4 and TSH showed no significant differences between the UIC $150-249 \mu \mathrm{g} / \mathrm{L}$ group and the other UIC groups.

\section{Thyroid functions of newborn}

All 79 pregnant women delivered their babies without complications, and boys accounted for $53.2 \%$ of the

Table 3 Prevalence of thyroid functions according to iodine status

\begin{tabular}{llllllll}
\hline Gestation & $N$ & $\begin{array}{l}\text { Normal } \\
\text { thyroid function }\end{array}$ & $\begin{array}{l}\text { Clinical } \\
\text { hypothyroidism }\end{array}$ & $\begin{array}{l}\text { Subclinical } \\
\text { hypothyroidism }\end{array}$ & $\begin{array}{l}\text { Clinical } \\
\text { hyperthyroidism }\end{array}$ & $\begin{array}{l}\text { Subclinical } \\
\text { hyperthyroidism }\end{array}$ & $\begin{array}{l}\text { Isolated } \\
\text { hypothyroxinemia }\end{array}$ \\
\hline 6th & 79 & $79(100 \%)$ & 0 & 0 & 0 & 0 & 0 \\
12 th & 79 & $72(91.14 \%)$ & 0 & $2(2.53 \%)$ & $1(1.27 \%)$ & $4(5.06 \%)$ & 0 \\
24 th & 78 & $73(93.59 \%)$ & $1(1.28 \%)$ & 0 & 0 & 0 & $4(5.13 \%)$ \\
32 th & 78 & $69(88.46 \%)$ & $1(1.28 \%)$ & $4(5.13 \%)$ & & $1(1.28 \%)$ & $3(3.85 \%)$ \\
Total & 314 & $293(93.31 \%)$ & $2(0.64 \%)$ & $6(1.91 \%)$ & $1(0.032 \%)$ & $5(1.59 \%)$ & $7(2.23 \%)$ \\
\hline
\end{tabular}


Table 4 Comparison of total dietary iodine intake in different gestation $(\mu \mathrm{g} / \mathrm{d})$

\begin{tabular}{llllll}
\hline Gestation & $N$ & Water iodine intake & Food iodine intake & Edible salt intake & Total iodine intake \\
\hline 12th & 79 & $3.12^{\mathrm{a}}(0.63 \sim 5.23)$ & $59.62(41.91 \sim 116.71)$ & $140.04(111.52 \sim 173.58)$ & $218.14(177.91 \sim 306.58)$ \\
24th & 79 & $3.58(1.05 \sim 6.12)$ & $63.22(42.52 \sim 104.35)$ & $153.25(126.96 \sim 216.63)$ & $233.51(184.04 \sim 345.74)$ \\
32th & 79 & $3.23(0.42 \sim 5.79)$ & $62.51(44.52 \sim 114.28)$ & $163.09(116.40 \sim 206.30)$ & $243.66(194.11 \sim 328.62)$ \\
F & & 1.12 & 0.33 & 2.75 & 0.22 \\
P value & 0.3092 & 0.6954 & 0.0674 & 0.7996 \\
Total & 3.24 & 62.22 & 152.03 & 231.17
\end{tabular}

${ }^{a}$ Median (inter-quartile range)

babies (Table 7). The average birth weight was $3310 \mathrm{~g}$ $(3050-3600 \mathrm{~g})$, and the average gestational age was 39 (38-40) weeks. Six of the newborns were preterm infants with gestational age less than 37 weeks. The average level of TSH from heel blood was $1.78 \mathrm{mIU} / \mathrm{L}$ (1.11$2.68 \mathrm{mIU} / \mathrm{L})$. Five babies had TSH higher than $5 \mathrm{mIU} / \mathrm{L}$, the highest being $7.3 \mathrm{mIU} / \mathrm{L}$, which was still lower than the threshold of $10 \mathrm{mIU} / \mathrm{L}$ used as the screening cut-off value for clinical hypothyroidism.

\section{Discussion}

Our study results suggest that a region in which the USI target has been reached in the long term, the MUIC of pregnant women being slightly less than $150 \mu \mathrm{g} / \mathrm{L}$ is probably sufficient to maintain iodine related biological functions in both women and their newborns. A study by Andersson [13] also validated that where USI has been effective for at least 2 years (with salt adequately iodized and consumed by more than $90 \%$ [14] of the population), it can be expected that the iodine stored in the thyroid gland of pregnant women is sufficient to ensure adequate thyroid function.

Although MUIC is one of the common indices to assess iodine status of a population, the most important physiological function of iodine is to participate in the synthesis of thyroid hormones. So, the key point of this study was to evaluate whether an MUIC value below $150 \mu \mathrm{g} / \mathrm{L}$ will affect the thyroid function in pregnant women and their newborns and whether the current
MUIC level $(107.41 \mu \mathrm{g} / \mathrm{L})$ can maintain normal thyroid function during pregnancy.

In this study, TgAb- and TPOAb-positive individuals were not enrolled in order to avoid the potential confounding factor of patients with thyroid autoimmune diseases. FT3, FT4, and TSH were used to evaluate the status of thyroid function throughout the pregnancy. In our results, the FT3 and FT4 initially declined and were then maintained. This could have been caused by the increasing basal metabolic rate and thyroid hormone consumption seen with the progression of a pregnancy. The trimester-specific changes we saw were in accordance with studies done by Soldin [15] and Kahric [16]. One woman in the study had an FT4 result slightly below the normal range and a TSH result a little over the normal range as defined in our study. But when compared to the reference range used by Donnovan et al. [17], lab values were all in the normal range. In this subject, the indicators returned to reference range by the 32nd week without any treatment. Furthermore, the $\mathrm{Tg}$ and SI were within the normal range during the whole pregnancy, and her newborn's TSH was less than $5 \mathrm{mIU} / \mathrm{L}$, which could indicate the nutritional status of the mother. After consulting the endocrinologist who mainly diagnosed on the basis of experience and the blood tests, we determined that this subject did not need immediate medical intervention and could still be included in our analysis.

$\mathrm{Tg}$ was also detected across all 3 trimesters. The values of Tg and TSH both had a "U" shape tendency during

Table 5 Urinary iodine and urinary creatinine during different pregnancy

\begin{tabular}{llllllll}
\hline Gestation & $N$ & $\begin{array}{l}\text { V24h } \\
(\mathrm{ml})\end{array}$ & $\begin{array}{l}\mathrm{MUIC} \\
(\mu \mathrm{g} / \mathrm{L})\end{array}$ & $\begin{array}{l}\mathrm{UIE} \\
(\mu \mathrm{g} / \mathrm{d})\end{array}$ & $\begin{array}{l}\mathrm{MUC} \\
(\mathrm{g} / \mathrm{L})\end{array}$ & $\begin{array}{l}\text { UCE } \\
(\mathrm{g} / \mathrm{d})\end{array}$ & $\begin{array}{l}\text { UICr } \\
(\mu \mathrm{g} / \mathrm{g})\end{array}$ \\
\hline Total & 237 & $1863(1450 \sim 2395)$ & $107.41(83.84 \sim 150.13)$ & $200.11(152.75 \sim 265.50)$ & $0.54(0.43 \sim 0.72)$ & $1.06(0.90 \sim 1.24)$ & $195.70(102.81 \sim 146.65)$ \\
12 th & 79 & $1850(1425 \sim 2215)$ & $101.56(83.18 \sim 140.32)$ & $185.00(142.75 \sim 254.76)$ & $0.55(0.44 \sim 0.69)$ & $1.02(0.94 \sim 1.18)$ & $188.26(144.81 \sim 256.74)$ \\
24 th & 79 & $1900(1450 \sim 2500)$ & $108.00(85.14 \sim 137.00)$ & $209.10(153.88 \sim 270.00)$ & $0.53(0.40 \sim 0.69)$ & $1.05(0.85 \sim 1.24)$ & $204.88(160.39 \sim 272.21)$ \\
32 th & 79 & $1900(1400 \sim 2300)$ & $113.00(80.94 \sim 157.00)$ & $198.5(161.28 \sim 274.00)$ & $0.58^{\mathrm{b}}(0.45 \sim 0.88)$ & $1.08^{\mathrm{ab}}(0.92 \sim 1.32)$ & $195.70(142.80 \sim 233.94)$ \\
F & 1.69 & 1.16 & 1.82 & 3.62 & 5.39 & 1.82 \\
P value & 0.1878 & 0.3149 & 0.1652 & 0.03 & 0.01 & \\
\hline
\end{tabular}

${ }^{\mathrm{a}} p<0.05$ between each trimesters with the 12 th weeks; ${ }^{\mathrm{b}} p<0.05$ between each trimesters with the 24 th weeks; V24 $\mathrm{h}, 24-\mathrm{h}$ urine volume; MUIC, median urinary iodine concentration; UIE, urinary iodine excretion; MUC, median urine creatinine; UCE, median urine creatinine excretion; UICr, creatinine-adjusted urine iodine 
Table 6 Serum concentration of TSH, FT4, and Tg in different UIC groups

\begin{tabular}{llllllll}
\hline $\begin{array}{l}\text { UIC } \\
\text { group }\end{array}$ & $\mathrm{N}$ & $\begin{array}{l}\mathrm{FT3} \\
(\mathrm{pmol} / \mathrm{L})\end{array}$ & $\begin{array}{l}\mathrm{FT} 4 \\
(\mathrm{pmol} / \mathrm{L})\end{array}$ & $\begin{array}{l}\mathrm{TSH} \\
(\mathrm{m} / \mathrm{U} / \mathrm{L})\end{array}$ & $\begin{array}{l}\mathrm{TG} \\
(\mu \mathrm{g} / \mathrm{L})\end{array}$ & $\begin{array}{l}\mathrm{SI} \\
(\mu \mathrm{g} / \mathrm{L})\end{array}$ & $\mathrm{UIC}(\mu \mathrm{g} / \mathrm{L})$ \\
\hline$<100$ & $96(41.0 \%)$ & $4.01(2.88-5.03)$ & $13.64(10.05-18.53)$ & $1.39(0.06-3.29)$ & $9.97(8.85)$ & $71.5(45.25-111.88)$ & $77.91(32.02-98.97)$ \\
$100-109$ & $30(12.9 \%)$ & $4.11(3.34-7.02)$ & $13.64(10.18-24.98)$ & $1.34(0.01-2.63)$ & $8.32(5.64)$ & $71.5(49-118)$ & $104.07(100.68-110.34)$ \\
$110-149$ & $49(20.9 \%)$ & $3.99(3.21-5.07)$ & $12.86(9.35-16.67)$ & $1.33(0.14-3.59)$ & $9.59(8.80)$ & $68(44-101.75)$ & $123(111-149.24)$ \\
$150-249$ & $47(20.1 \%)$ & $4.00(3.21-5.25)$ & $13.06(9.08-17.60)$ & $1.48(0.12-2.93)$ & $8.12(9.91)$ & $70(39.8-105.8)$ & $175.71(150.05-237.39)$ \\
$250-499$ & $12(5.1 \%)$ & $3.95(3.29-9.87)$ & $12.55(11.04-22.14)$ & $1.55(0.01-2.88)$ & $7.73(3.85)^{*}$ & $78(63-123)^{*}$ & $304.29(259.00-471)$ \\
\hline
\end{tabular}

${ }^{*} P$ values represent the median level of this group compared with the 150-249 group

the whole pregnancy, which could be affected by human chorionic gonadotropin (HCG). HCG can have a thyroid stimulating effect [18]. It can competitively inhibit the excretion of TSH [19] and cause the increase of $\mathrm{Tg}$ [20]. Some studies $[21,22]$ indicate that if iodine deficiency exists in the body, the concentration of $\mathrm{Tg}$ will increase correspondingly, and the change of $\mathrm{Tg}$ concentration is more sensitive than that of goiter. Although there is no consensus for the reference intervals of Tg during pregnancy, $\geq 13 \mu \mathrm{g} / \mathrm{L}$ is commonly used when assessing iodine deficiency in pregnant women [23]. In our study, serum $\mathrm{Tg}$ levels were negatively correlated with urinary iodine level $(r=-0.14)$. Mild to moderate iodine deficiency may be associated with elevated serum $\mathrm{Tg}$. $\mathrm{Tg}$ levels of our participants in all 3 trimesters were less than $13 \mu \mathrm{g} / \mathrm{L}$, and the median $\mathrm{Tg}$ was $11.8 \mu \mathrm{g} / \mathrm{L}$. According to Moleti et al. [24], the median $\mathrm{Tg}$ level was $10.2 \mu \mathrm{g} / \mathrm{L}$ which is similar to the finding in our study.

Serum iodine was another biomarker used to monitor the iodine status of our volunteers. This reflects the level of bioactive iodine ions that can be utilized by thyroid tissue in vivo [25]. It was reported as a relatively stable index and not able to be readily changed with diet [25]. The correlation analysis also shows a strong positive relationship between SI and FT4, especially at 32 weeks' gestation $(r=0.734, P<0.05)$. Similar to $\mathrm{Tg}$, there is also no unified threshold for SI. The recommended reference range from the $\mathrm{WHO}$, the Mayo Clinic, and other studies is $45-90 \mu \mathrm{g} / \mathrm{L}, 52-109 \mu \mathrm{g} / \mathrm{L}$, and $36-97 \mu \mathrm{g} / \mathrm{L}$, respectively. The distribution of SI in our study was $44-109 \mu \mathrm{g} / \mathrm{L}$.

The serum concentrations of thyroid function indexes were compared in different UIC groups. The 150$249 \mu \mathrm{g} / \mathrm{L}$ UIC group, the range recommended by the WHO, was used as the reference group. Except for $\mathrm{Tg}$ and SI in the $250-499 \mu \mathrm{g} / \mathrm{L}$ UIC group, there was no

Table 7 Basic information of the newborns

\begin{tabular}{lllllll}
\hline Indexes & N & Min & P25 & P50 & P75 & Max \\
\hline gestation & 79 & 33 & 38 & 39 & 40 & 41 \\
weight(g) & 79 & 1510 & 3050 & 3310 & 3600 & 4370 \\
TSH(mIU/L) & 79 & 0.25 & 1.11 & 1.78 & 2.68 & 7.30 \\
\hline
\end{tabular}

significant difference by UIC level. Thus, our hypothesis suggests that iodine intake in early pregnancy could be UIC less than $150 \mu \mathrm{g} / \mathrm{L}$. These findings were consistent with the results in the lower iodine intake groups of Xiaoguang Shi [26].

Dietary iodine intake is an important index for evaluating iodine nutritional status. Our results showed that the average total dietary iodine intake in this study was $231.17 \mu \mathrm{g} / \mathrm{d}$. This value reached the recommended nutrient intake (RNI) of iodine for Chinese pregnant women $(230 \mu \mathrm{g} / \mathrm{d})$ [27].

Dietary iodine intake fluctuates greatly according to what the individual ate before antenatal care, so after each visit and collection of the dietary intake log, we provided feedback about the results and gave professional advice about her dietary intake. Our study subjects knew more about the important role and the additional requirement of iodine in pregnancy after receiving our training during the study. The majority reported that they returned to buying iodized salt for their family again.

MUIC has been widely used to assess the iodine status of a population [28]. According to urinary iodine excretion accounted for $90 \%$ of total iodine excretion [29, 30], $200.11 \mu \mathrm{g} / \mathrm{d}$ UIE means the $222.34 \mu \mathrm{g} / \mathrm{d}$ iodine loses per day. Compared with the total dietary iodine intake was $231.17 \mu \mathrm{g} / \mathrm{d}$ (Table 4), the urinary losses suggest pregnant women in our study were in a positive balance of iodine metabolism during the whole pregnancy. These two methods for evaluating the iodine intake status both indicated that subjects in our study had good dietary iodine intake.

All the data suggest that the pregnant women in our study have the appropriate iodine nutritional status. Their median UIC during the whole gestation period was about $110 \mu \mathrm{g} / \mathrm{L}$, with no significant differences among trimesters.

Neonatal heel blood TSH was another recommended indicator for iodine status by WHO/UNICEF/ICCIDD [4]. A TSH value of $10 \mathrm{mIU} / \mathrm{L}$ is widely used as the screening cut-off for clinical hypothyroidism. The WHO also points out that less than $3 \%$ of neonatal heel blood $\mathrm{TSH}>5 \mathrm{mIU} / \mathrm{L}$ could indicate overall iodine sufficiency in a region $[5,31]$. Our study had 5 babies $(6.3 \%)$ who had 
a heel blood TSH higher than $5 \mathrm{mIU} / \mathrm{L}$. Although the percentage is higher than $3 \%$, all the detection values were lower than the $10 \mathrm{mIU} / \mathrm{L}$ cut-off. Some studies [32, 33] found that when screening neonatal TSH areas with sufficient iodine, many regions had a frequency of TSH $>5$ $\mathrm{mIU} / \mathrm{L}$ higher than 3\%. Although several studies have attempted to find the influence of iodine deficiency on child neurobehavioral development, there are no data available from any randomized controlled clinical trials linking prenatal iodine supplementation and child neurobehavioral development in regions of mild to moderate iodine deficiency [34].

Taking all this information together, we conclude that all the pregnant women in our cohort study had good thyroid function across trimesters.Our study suggests that in China, high and long-term coverage with adequately iodized salt might justify a different cut-off for MUIC, especially for pregnant women.

A major strength of this study is that we collected 24-h urine samples during all trimesters and analyzed it for iodine and creatinine at the same time to correct the effects of incomplete sample collection. The sodium content of the 24-h urine collection was also used to get more accurate salt intake information in this study. Although a morning spot urine was used for screening at 6 weeks, the WHO/UNICEF/ICCIDD joint task force indicates that iodine concentrations measured in urine samples collected in the morning, or from other spot urine collections, have been shown to adequately assess a population's iodine status $[4,35]$. Therefore, the collected urinary samples are representative during the whole gestation. Second, thyroid function during pregnancy was monitored throughout gestation, even extending to the newborn's heel blood TSH. Besides the general indictors, Tg and SI were also used to assess thyroid function. We excluded individuals with positive TPOAb and TgAb. Third, detailed dietary iodine intake from foods, drinking water, soup, and salt were analyzed in our study. Positive iodine metabolism balance gives us more confidence about our results.

However, this study does have some limitations. For the limited time and budget, our sample size of 79 is relatively small. Further multi-centered clinical research is needed to verify our results. Another limitation is lack of clarity about the iodine in salt used to make processed foods. Relevant research of iodine concentration in processed food is underway.

\section{Conclusions}

In this study, with over 20 years implementing of universal salte iodization in China, the expectant mothers with the MUIC $107.4 \mu \mathrm{g} / \mathrm{L}$, which was less than $150 \mu \mathrm{g} / \mathrm{L} \mathrm{rec-}$ ommended by WHO, can also maintain the normal iodine nutritional status for both of the pregnant women and their newborn babies.

\section{Abbreviations}

FT3: Free Triiodothyronine; FT4: Free Thyroxine; MUC: median urine creatinine; MUIC: median urinary iodine concentration; SI: serum iodine; TG: thyroid globulin; TGAb: thyroglobulin antibody; TPOAb: thyroid peroxidase antibody; TSH: Thyroid Stimulating Hormone; UCE: median urine creatinine excretion; UICr: creatinine-adjusted urine iodine; UIE: urinary iodine excretion; USI: universal salt iodization; V24 h: 24-h urine volume

\section{Acknowledgements}

Special appreciation will send to Dr. Nancy Potischman, who gave us a lot of inspiring suggestions and help to polish and modify this manuscript. Dr. Potischman is the Director of Population Studies, in the Office of Disease Prevention in the Office of the Director of the National Institutes of Health.

\section{Authors' contributions}

$\mathrm{HZ}$ and $\mathrm{MW}$ were responsible for all the details of this study, including analysis data and draft this article. JW and $\mathrm{YH}$ took part in the recruitment of participants and follow up. JH tested all the biomarkers in blood samples.

$Y G, X L$ and HW detected the iodine level in urine,water and salt samples. LY, $L M$ and $X Y$ all took part in designing this study and acted as the cocorresponding authors. LY also contributed a lot in the process for revising this manuscript, LM answered for all the clinical follow-up and guidance. All authors read and approved the final manuscript.

\section{Funding}

This study was supported by United Nations International Children's Emergency Fund (UNICEF).

\section{Availability of data and materials}

Please contact author (Lichen Yang) for data or material requests.

\section{Ethics approval and consent to participate}

All the women were recruited following the informed consent and ethical review.

\section{Consent for publication}

The authors consent to the publication of the data.

\section{Competing interests}

The authors declare that they have no competing interests.

\section{Author details}

${ }^{1}$ The Key Laboratory of Trace Element Nutrition, National Institute for Nutrition and Health, Chinese Center for Disease Control and Prevention, 29 Nan Wei RoadXicheng District, Beijing, China. ${ }^{2}$ Shaanxi Provincial Centre for Disease Control and Prevention, No.3, jiandong street, Xi'an, Shaanxi, China. ${ }^{3}$ The Department of Laboratory Medicine, Peking Union Medical College Hospital, Chinese Academic Medical Science and Peking Union College, No.1 Shuaifuyuan WangfujingDongcheng District, Beijing, China. ${ }^{4}$ The National IDD Reference Laboratory, National Institute for Nutrition and Health, Chinese Center for Disease Control and Prevention, 29 Nan Wei RoadXicheng District, Beijing, China. ${ }^{5}$ Department of Obstetrics-gynecology, Peking Union Medical College Hospital, No.1 Shuaifuyuan

WangfujingDongcheng District, Beijing, China.

Received: 27 August 2018 Accepted: 12 August 2019

Published online: 09 September 2019

\section{References}

1. Glinoer D. The regulation of thyroid function during normal pregnancy: importance of the iodine nutrition status. Best Pract Res Clin Endocrinol Metab. 2004;18(2):133-52.

2. WHO, G.S.E., Indicators for assessing iodine deficiency disorders and their control through salt iodization. World Health Organization, 1994.

3. Stanbury JB, Hetzel BS. Endemic goiter and endemic cretinism; iodine nutrition in health and disease; 1980.

4. WHO/UNICEF/ICCIDD. Assessment of iodine deficiency disorders and monitoring their elimination: a guide for programme managers, 3. Geneva: World Health Organization; 2007. (http://whqlibdoc.who.int/publications/2 007/9789241595827_eng.pdf, Accessed 13 June 2019). 
5. Zhao J, Van DHF. Progress in salt iodization and improved iodine nutrition in China, 1995--99. Food Nutr Bull. 2004;25(4):337.

6. Wang $Y$, et al. lodine deficiency disorders after a decade of universal salt iodization in a severe iodine deficiency region in China. Indian J Med Res. 2009;130(4):413-7

7. Sun DJ, Lei ZL, Liu SJ. 2014 National lodine Deficiency Disorders Surveillance. Beijing: People's Medical Publishing House; 2017.

8. Stagnaro-Green A, et al. Guidelines of the American Thyroid Association for the diagnosis and management of thyroid disease during pregnancy and postpartum. Thyroid. 2011;21(10):1081-125.

9. $\mathrm{MB} Z$, et al. Increasing the iodine concentration in the Swiss iodized salt program markedly improved iodine status in pregnant women and children: a 5-y prospective national study. Am J Clin Nutr. 2005;82(2):388.

10. Eastman CJ, Zimmermann M. The iodine deficiency disorders; 2009. p. 25-31.

11. Organization, W.H. and UNICEF. Assessment of iodine deficiency disorders and monitoring their elimination: a guide for programme managers. 2nd ed; 2001.

12. Perrine CG, et al. Comparison of population iodine estimates from 24-hour urine and timed-spot urine samples. Thyroid. 2014;24(4):748-57.

13. Andersson $\mathrm{M}, \mathrm{De} B \mathrm{~B}$, Delange $\mathrm{F}$, et al. Prevention and control of iodine deficiency in pregnant and lactating women and in children less than 2years-old: conclusions and recommendations of the technical consultation[J]. Public Health Nutr. 2007;10(12A):6.

14. WHO/UNICEF/ICCIDD. Assessment of iodine deficiency disorders and monitoring their elimination: a guide for programme managers, 2. Geneva: World Health Organization; 2001. (http://whqlibdoc.who.int/hq/2001/WHO_ NHD_01.1.pdf, Accessed 13 June 2019).

15. Soldin OP, et al. Trimester-specific changes in maternal thyroid hormone, thyrotropin, and thyroglobulin concentrations during gestation: trends and associations across trimesters in iodine sufficiency. Thyroid. 2004;14(12):1084-90.

16. Kahric-Janicic $\mathrm{N}$, et al. Tandem mass spectrometry improves the accuracy of free thyroxine measurements during pregnancy. Thyroid. 2007;17(4):303-11.

17. Donovan $L D$, et al. A practical approach for the verification and determination of site and trimester specific reference intervals for thyroid function tests in pregnancy. Thyroid. 2018

18. De Groot $L$, et al. Management of thyroid dysfunction during pregnancy and postpartum: an Endocrine Society clinical practice guideline. J Clin Endocrinol Metab. 2012;97(8):2543-65.

19. Koulouri $\mathrm{O}$, et al. Diagnosis and treatment of hypothyroidism in TSH deficiency compared to primary thyroid disease: pituitary patients are at risk of under-replacement with levothyroxine. Clin Endocrinol. 2011;74(6):744-9.

20. Costeira MJ, et al. Parameters of thyroid function throughout and after pregnancy in an iodine-deficient population. Thyroid. 2010;20(9):995-1001.

21. Zimmermann MB, et al. Development of a dried whole-blood spot thyroglobulin assay and its evaluation as an indicator of thyroid status in goitrous children receiving iodized salt. Am J Clin Nutr. 2003;77(6):1453-8.

22. Zimmermann MB, et al. Thyroglobulin is a sensitive measure of both deficient and excess iodine intakes in children and indicates no adverse effects on thyroid function in the UIC range of 100-299 $\mu \mathrm{g} / \mathrm{L}$ : a UNICEF/ ICCIDD study group report. J Clin Endocrinol Metab. 2013;98(3):1271-80.

23. Raverot $\mathrm{V}$, et al. Pregnant French women living in the Lyon area are iodine deficient and have elevated serum thyroglobulin concentrations. Thyroid. 2012;22(5):522-8.

24. Moleti, et al. lodine prophylaxis using iodized salt and risk of maternal thyroid failure in conditions of mild iodine deficiency. J Clin Endocrinol Metab. 2008;93(7):2616-21.

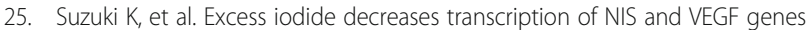
in rat FRTL-5 thyroid cells. Biochem Biophys Res Commun. 2010;393(2):286-90.

26. Xiaoguang $\mathrm{S}$, et al. Optimal and safe upper limits of iodine intake for early pregnancy in iodine-sufficient regions: a cross-sectional study of 7190 pregnant women in China. J Clin Endocrinol Metab. 2015;100(4):1630-8.

27. Chinese Nutrition Society. Chinese dietary reference intakes (2013)[m]: Science Press; 2014.

28. Chitalia VC, et al. Cost-benefit analysis and prediction of 24-hour proteinuria from the spot urine protein-creatinine ratio. Clin Nephrol. 2001;55(6):436-47.

29. Zimmermann MB, Andersson M. Assessment of iodine nutrition in populations: past, present, and future. Nutr Rev. 2012;70(10):553-70.

30. Micronutrients, I.O.M.P., Dietary reference intakes for vitamin a, vitamin K, arsenic, boron, chromium, copper, iodine, Iron, manganese, molybdenum, nickel, silicon, vanadium, and zinc. 2001: National Academy Press. 294-301.

31. Zimmermann MB. lodine deficiency in pregnancy and the effects of maternal iodine supplementation on the offspring: a review. Am J Clin Nutr. 2009;89(2):668S-72S
32. Xiao Hui SU, et al. Chinese neonatal umbilical cord blood TSH level: Chinese Jouranl of Endemiology; 2001.

33. Yan-Li MA, Qin LY, Tang YD. The applying study on the neonate screening TSH cut-off. Maternal \& Child Health Care of China. 2006.

34. Pearce EN, et al. Consequences of iodine deficiency and excess in pregnant women: an overview of current knowns and unknowns. Am J Clin Nutr. 2016;104(3).

35. WHO. Urinary iodine concentrations for determining iodine status deficiency in populations. Vitamin and Mineral Nutrition Information System. Geneva: World Health Organization; 2013 (http://www.who.int/ nutrition/vmnis/indicators/urinaryiodine, Accessed 13 June 2019).

\section{Publisher's Note}

Springer Nature remains neutral with regard to jurisdictional claims in published maps and institutional affiliations.
Ready to submit your research? Choose BMC and benefit from:

- fast, convenient online submission

- thorough peer review by experienced researchers in your field

- rapid publication on acceptance

- support for research data, including large and complex data types

- gold Open Access which fosters wider collaboration and increased citations

- maximum visibility for your research: over $100 \mathrm{M}$ website views per year

At $\mathrm{BMC}$, research is always in progress.

Learn more biomedcentral.com/submissions 